\title{
Masculinidades dissidentes na copa do mundo do jornal “Folha de São Paulo"
}

\author{
André Luiz dos Santos Silva ${ }^{\circledR}{ }^{\bullet}$, Rafael Goulart Dullius ${ }^{\natural}{ }^{\oplus}$, Gustavo Roese Sanfelice $^{\mathrm{c} \odot}$
}

\section{Keywords:}

Deviant Manliness;

Folha de São Paulo;

Football;

Gender.

\section{Palavras-chave:}

Masculinidades

dissidentes;

Folha de São Paulo;

Futebol.

Gênero

\begin{abstract}
This article takes the publications of Folha de São Paulo as empirical material to analyze representations of dissident masculinities in relation to the sports results of the Brazilian team in the World Cup / 2014. Methodologically, the representations of non-heterocentered masculinities were articulated chronologically to the results of the games and analyzed based on post-structuralist approaches to Gender. As a result, insufficient sporting performance seems to have been a marker of the emergence of dissidents who, in tones of mockery, would serve to regulate conduct, reinforce gender hierarchies and produce feelings of social justice, reiterating as an effect, the male and heteronormative matrix in football.
\end{abstract}

\section{RESUMO}

Este artigo toma as publicações da Folha de São Paulo como material empírico para analisar representações de masculinidades dissidentes em relação aos resultados esportivos da Seleção Brasileira na Copa do Mundo/2014. Metodologicamente, as representações de masculinidades não heterocentradas foram articuladas cronologicamente aos resultados dos jogos e analisadas com base nas abordagens pós estruturalistas de Gênero. Como resultado, a performance esportiva insuficiente parece ter sido balizadora da emergência dos dissidentes que, em tons de zombaria, serviriam para regular condutas, reforçar hierarquias de gênero e produzir sentimentos de justiça social, reiterando como efeito, a matriz masculina e heteronormativa no futebol.

\section{Resumen}

Este artículo toma las publicaciones de Folha de São Paulo como material empírico para analizar representaciones de masculinidades disidentes en relación con los resultados deportivos del equipo brasileño en la Copa del Mundo / 2014. Metodológicamente, las representaciones de masculinidades no heterocentradas se vincularon cronológicamente a los resultados de los juegos y se analizaron en base a enfoques de género postestructuralistas. Como resultado, el rendimiento deportivo insuficiente parece haber sido un marcador de la aparición de disidentes que, en tono de burla, servirían para regular la conducta, reforzar las jerarquías de género y producir sentimientos de justicia social.

\footnotetext{
a Universidade Federal do Rio Grande do Sul, Departamento de Educação Física, Fisioterapia e Dança; Porto Alegre, Rio Grande do Sul; Brasil.

' Secretaria de Educação do Município de Sapiranga; Sapiranga, Rio Grande do Sul, Brasil.

' Universidade Feevale, Programa de Pós Graduação em Diversidade Cultural e Inclusão Sociais; Novo Hamburgo, Rio Grande do Sul, Brasil.
}

Autor correspondente:

André Luiz dos Santos Silva

E-mail: andrels@ufrgs.br

Recebido em 11 de Maio de 2020; aceito em 29 de Maio de 2020. 


\section{INTRODUÇÃO}

A Copa do Mundo (FIFA) é considerada o segundo maior evento esportivo do planeta e a competição internacional de Futebol mais importante do mundo. Como condição necessária para sua realização e, sobretudo, para a exploração máxima de seu potencial, o evento tem recebido constantes coberturas midiáticas, cujos investimentos e programações têm construído diversos significados na relação com o campo esportivo (Mezzaroba; Pires, 2011).

Assim, apoiados em Sanfelice et al. (2014), que nos aponta sobre os sentidos produzidos pelas coberturas midiáticas esportivas, em Sabat (2001) e em Costa e Andrade (2015), que versam sobre as pedagogias culturais das mídias, foi possível perceber que, mediante as formas de enquadramento, os meios de comunicação estabelecem relação com os receptores/consumidores, cujo elemento aglutinador se situa nas especificidades culturais em que estão inseridos. Em vista disso, o processo de comunicação se estabelece por intermédio de um conjunto de representações agenciadas por relações de poder que atuam diretamente nos processos de produção de sentidos. Enquanto intermediária da comunicação, as produções midiáticas vêm (re)significando complexos sistemas de representação como raça/etnia, classe social, sexualidade e gênero, entre outros. Assim, a articulação entre mídia e esporte, especialmente, o futebol, tem construído lugares e sentidos de gênero, os quais são altamente hierarquizados.

Concebido por homens e para homens, o futebol tem sido historicamente associado ao universo masculino heterossexual, apresentando barreiras às mulheres (Goellner, 2005) e aos homens que não condizem com o modelo de "masculinidade adequada" (Camargo, 2014). Assim, considerando o futebol como prática cultural marcadamente masculina/ heterocentrada, e partindo do entendimento de que a mídia opera como uma pedagogia cultural de gênero e sexualidade, este texto toma as produções midiáticas do jornal "Folha de São Paulo" como material empírico para analisar representações de masculinidades dissidentes e suas relações com os resultados esportivos da Seleção Brasileira durante a cobertura da Copa do Mundo/FIFA/Brasil.

Foram acessadas as edições online da 'Folha', entre 12 de junho a 13 de julho de 2014, período

\footnotetext{
${ }^{1}$ Em 2014, a "Folha de São Paulo" foi o jornal brasileiro de maior média de circulação. Segundo a Associação Nacional de Jornais (ANJ), a 'Folha' contabilizou uma média de 351.745 , entre publicações impressas e digitais, sendo seguida pelo "O Globo" do Rio de Janeiro, com 333.860 e "Super Notícia", de Minas Gerais, com 318.067. O Grupo Folha detém a maior empresa brasileira de conteúdo e serviços
}

que compreendeu os jogos da competição. Num primeiro momento, procedeu-se a leitura geral do material, identificando as publicações referentes à Copa do Mundo, atravessadas por marcadores de masculinidades, com especial atenção às 'não normativas'. Nesse processo, foram consideradas imagens, editoriais, painéis, títulos, capas, notícias e notas nos diversos cadernos do jornal [Opinião, Poder, Mundo, Mercado, Cotidiano, Esporte, Ilustrada, Turismo, Guia Folha, Folha Invest, Folha Corrida, Caderno Tec e Folhinha].

A partir desse primeiro acesso, os dados referentes à proposta deste texto, [publicações 6, 7, 9 e 10] foram 'pinçados' e organizados com a intenção de evidenciar possíveis relações entre a campanha da seleção brasileira na competição e a emergência de representação de masculinidades dissidentes associadas aos atletas do Brasil. Os processos metodológicos que permitiram a tessitura deste texto foram conduzidos pelo entendimento de que as produções midiáticas se constituem na linguagem (Ribeiro; Siqueira, 2007; Sabat, 2001) enquanto locus de disputa, de exercícios de poder e suas resistências (Foucault, 2013). Assim, o jornal "Folha de São Paulo" e suas publicações não são compreendidos como um reflexo da sociedade onde estão inseridos, mas, sim, como representações carregadas de instabilidades, provisoriedades e sentidos diversos que colocam em operação representações e práticas discursivas ${ }^{2}$ (Meyer; Soares, 2004). Tais entendimentos fundamentam a abordagem analítica deste texto, que coloca em evidência um sistema linguístico que ao mesmo tempo produz e é produzido por relações de gênero capazes de regular condutas e construir identidades, forjando representações e práticas (Hall, 1997).

Nesse sentido, o conceito de gênero contrapõese às premissas que sustentam os agenciamentos da biologia na produção de feminilidades e masculinidades (Laqueur, 2001). Como um organizador do social e da cultura, gênero se constrói nas relações de poder localizadas nas diferentes instâncias sociais e nas especificidades de cada momento histórico (Meyer, 2005; Scott, 1995). Por meio de mecanismos linguísticos, as tecnologias de gênero produzem lugares

de internet, a UOL, controla o site de notícias mais acessado, o Folha. com, e a maior gráfica comercial do Brasil, a Plural. Responsável por um dos institutos de pesquisa mais respeitados do país, o "Datafolha", o grupo possui a "Publifolha", uma importante editora de livros, uma livraria virtual, a Livraria da Folha e uma agência de notícias, a "Folhapress" (Kuhn Junior et al., 2015).

${ }^{2}$ Cabe ressaltar, entretanto, que, se é possível conceber a mídia como elemento constituidor do processo de formação dos sujeitos, a assimilação e recepção de suas mensagens não ocorrem de forma passiva, mas por meio de um processo de negociação e resistência (Fischer, 2002). 
Quadro 1. Masculinidades dissidentes na Folha de São Paulo

\begin{tabular}{lcccc}
\hline & AUTORIA & DATA & TíTULO & PÁGINA \\
\hline $\mathbf{1}$ & Sandro Macedo & $12 / 06 / 2014$ & Faça sua Tabela & D2 e D3 \\
$\mathbf{2}$ & Sandro Macedo & $13 / 06 / 2014$ & Sexta-feira 13 & D2 \\
$\mathbf{3}$ & Sandro Macedo & $16 / 06 / 2014$ & Isso é Cris Ronaldo & D2 \\
$\mathbf{4}$ & Sandro Macedo & $17 / 06 / 2014$ & Schumi na copa & D2 \\
$\mathbf{5}$ & Sandro Macedo & $18 / 06 / 2014$ & O que você já viu & D2 \\
$\mathbf{6}$ & José Simão & $19 / 06 / 2014$ & Selecinha! Culpa da L'Oreal & E9 \\
$\mathbf{7}$ & Allan Sieber & $26 / 06 / 2014$ & Os figurinhas do Polca & E9 \\
$\mathbf{8}$ & Sandro Macedo & $30 / 06 / 2014$ & Olho no telão & D2 \\
$\mathbf{9}$ & Allan Sieber & $02 / 07 / 2014 a$ & A Volta do antigo Felipão & D2 \\
$\mathbf{1 0}$ & Allan Sieber & $02 / 07 / 2014 b$ & Musas do Polca & E11 \\
\hline
\end{tabular}

Fonte: Produzida pelos autores.

e hierarquizações distintas às distintas identidades, gerando como efeito expectativas que estimulam e inibem modos de ser e se portar, produzindo sujeitos a partir desses processos de regulação ${ }^{3}$ (ladevito, 2014; Preciado, 2009; Swain, 2001). Cabe ressaltar, entretanto, que esse processo abre brechas a outras possibilidades de existência, produzindo, por meio das relações de poder fissuras nas normativas de gênero. Neste sentido, toma-se de empréstimo a noção de dissidência proposta por Figari (2009) e Figari e DíazBenítes (2009) como ferramenta descritiva e analítica de um tipo de masculinidade representada como abjeta pelo jornal. À margem do binarismo sexual, as masculinidades dissidentes não são fixas aos marcadores que diferenciam homens e mulheres. Sua materialidade discursiva é marcada pela incorporação do que historicamente se reconhece como feminino, produzindo uma textualidade desprezível em termos de gênero e sexualidade. As masculinidades dissidentes podem ser compreendidas, portanto, como o exterior abjeto que constitui a heteronormatividade ${ }^{4}$ enquanto categoria quase única no futebol.

Partindo desses pressupostos teórico/ metodológicos, este texto evidencia as hierarquias constituídas pelas representações de masculinidades cujas articulações com o futebol e com a copa do mundo reiteram representações heterocentradas. De modo breve e em número reduzido, a emergência das 'masculinidades dissidentes' parece ser balizada por um conjunto de condições que cerceiam os motivos

\footnotetext{
${ }^{3}$ Produzidas nas relações de poder que se estabelecem em momentos históricos e contextos específicos, as tecnologias gênero, ao passo que incentivam e constrangem distintas subjetividades, são do mesmo resistidas, produzindo outros projetos, gerando outros efeitos nas experiências dos sujeitos (Foucault, 2013).

4 "A heteronormatividade atua como um sistema de verdade" (Britzmann, 1996, p. 79) que naturaliza o trinômio sequencial sexo-gênero-sexualidade. É centrada na heterossexualidade ao mesmo tempo em que regula e é regulada pelas normas de gênero (Sales; Paraíso, 2013).
}

e os modos pelos quais são mencionadas no jornal "Folha de São Paulo".

\section{Quando o desempenho não é suficiente: gaymara e as "bailarinas da seleção brasileira"}

O mês que antecedeu os jogos da Copa foi marcado por um sentimento de quase euforia e otimismo. Os grandes investimentos em infraestrutura, a organização final do espetáculo e as notícias, em tom de confiança acerca da Seleção Brasileira de Futebol, marcaram o modo como a Folha de São Paulo tratou a prévia dos Jogos (Dieder et al., 2016; Brinati, 2014). Assim como sinalizaram Escher e Reis (2008), em 2014, as páginas da 'Folha' deram a ver manifestações de nacionalismo que colocavam em evidência o futebol como elemento identitário do povo brasileiro.

Nesse clima, iniciaram-se os jogos que, em sua fase inicial, obteve uma das mais altas médias de gols da história da competição. Segundo Dieder et al. (2016, p. 1178), "com a marca de 2,83 gols por jogo, a primeira fase do mundial registrou a maior média desde 1958". Além disso, as equipes representantes dos países sul americanos apresentaram, no início dos jogos, desempenho surpreendente ${ }^{5}$.

No caso do Brasil, entretanto, entusiasmo com a seleção brasileira, parece ter cedido lugar à decepção e à contrariedade desde as primeiras partidas. Assim, Marcelo Vieira, lateral esquerdo, ao abrir o placar do primeiro jogo com um gol contra, parece ter dado o teor do que seria o desempenho da seleção na competição. Mesmo com o resultado de 3 a 1 sobre a Croácia, o que pareceu ser um placar razoável, o desempenho da equipe já inspirava dúvidas e crítica desde a primeira partida.

Na segunda rodada dos jogos, o resultado de 0 a 0 contra o México resultou também em empate na tabela

\footnotetext{
${ }^{5}$ Destacam-se os resultados dos Jogos de Chile $3 \times 1$ Austrália, Colômbia 3×0 Grécia, Uruguai 2x1 Inglaterra e Chile 2x0 Espanha.
} 


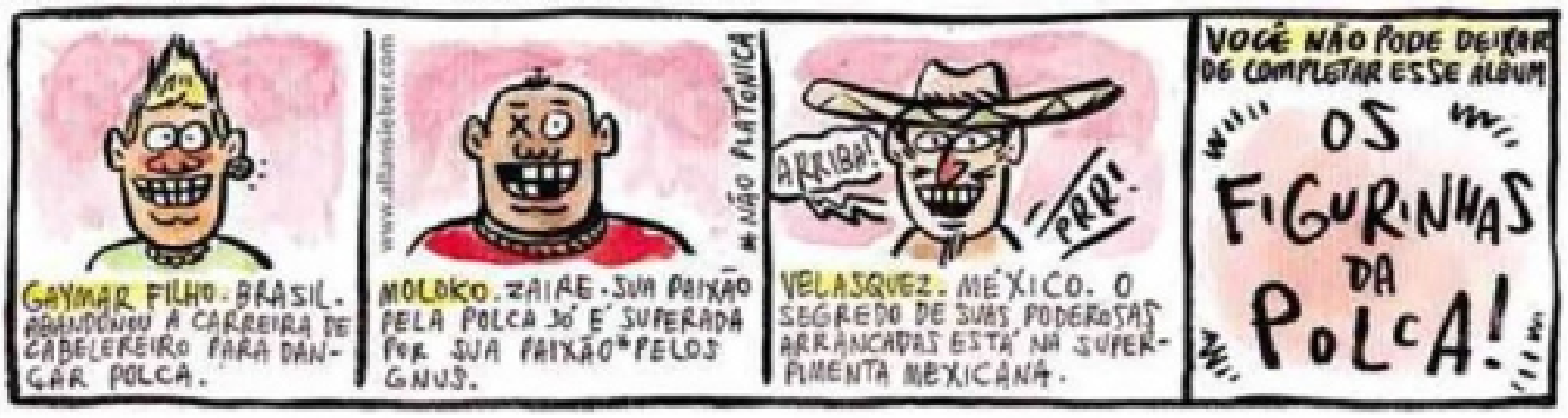

Imagem 1. "Os Figurinhas da Polca"

Fonte: Sieber - Folha de São Paulo, 26/06/2014, p.E9

de classificação. Até então ambas as equipes possuíam 4 pontos contabilizados e o desempenho considerado mediano da equipe brasileira teria gerado um clima de insegurança acerca dos resultados dos próximos jogos e da classificação final na "fase de grupos"6.

Assim, desde o início o desempenho insuficiente teria gerado, como efeito, uma mudança no modo como o jornal "Folha de São Paulo" passou a discutir a seleção. O orgulho nacional e o futebol como elemento identitário do povo brasileiro deram espaço aos argumentos que evidenciavam "o nervosismo, a instabilidade emocional, o choro e a luta" (Dieder et al., 2016, p. 1178). Entretanto, ao analisar as publicações da 'Folha', a partir da categoria gênero, foi possível perceber que o descontentamento acerca da performance dos atletas parece ter colocado em funcionamento a zombaria como mecanismo ${ }^{7}$ que teria como intenção regular condutas, reforçar hierarquias de gênero e produzir um sentimento de justiça social. Nesse processo, o jornal faz uso da paródia ${ }^{8}$ como recurso linguístico que qualifica como 'dissidentes' as masculinidades daqueles considerados responsáveis pelo mal desempenho do Brasil.

\footnotetext{
${ }^{6}$ A competição foi organizada em duas fases: "Fase de grupos" e "fase final" ("Oitavas de final"; "Quartas de final"; "Semi-final"; "Disputa de 3 lugar" e "Final". A primeira foi organizada a partir de 8 grupos nomeados de $\mathrm{A}$ a $\mathrm{H}$ e cuja composição se deu por meio de um conjunto de regras e sorteios. Por ser país sede, o Brasil, tornou-se a primeira de 4 equipes do Grupo A, cujos jogos aconteceram do dia 12 a 23 de junho.

7 Esse argumento é fundamentado pela articulação entre "as relações jocosas futebolísticas" (Gastaldo, 2010) e os conceitos de "tecnologia da zuação" (Sales; Paraíso, 2013), e de "humilhação" (Díaz-Benítes, 2019).

${ }^{8}$ Paródia, neste texto, não deve ser entendido como uma produção ficcional a partir do real, mas um modo de representação, um recurso que coloca em funcionamento relações de gênero. No caso deste estudo, a paródia permite reafirmar um código de conduta sobre aquilo que é adequado e desqualificado nas performances de gênero no campo do futebol (Louro, 2008; Butler, 2003).
}

Assim, dois dias antes doúltimojogo do Brasil na "fase de grupos", Neymar, ídolo máximo da seleção brasileira, torna-se o principal alvo de zombaria homofóbica no Jornal, posto, até então, ocupado exclusivamente por Cristiano Ronaldo. Cabe ressaltar que antes mesmo dos primeiros Jogos da Equipe Portuguesa, charges, matérias e notas sobre a conduta pouco discreta e muito vaidosa de Cristiano Ronaldo foram publicadas, dando a ver que para o atleta português não seria a performance insuficiente que acionaria a chacota. No caso da seleção brasileira, entretanto, a condução do jornal configurou-se outra. Apesar de Neymar, por exemplo, ser reconhecido como vaidoso, pouco discreto e adepto de práticas de embelezamento, a zombaria homofóbica e misógina só foi acionada como punição ao desempenho insatisfatório.

Deste modo, Neymar e a seleção brasileira passaram a ser alvos de "troça" na medida em que o desempenho esportivo, bem como a conduta "chorosa" e a "falta de garra" geravam contrariedade às expectativas.

Cronologicamente, as publicações do jornal que ironizam as masculinidades dos atletas da seleção brasileira foram divulgadas dias antes de jogos decisivos. Nesse sentido, no dia 19/06, dois dias após o 0x0 entre Brasil e México, José Simão ${ }^{9}$ publica, no Caderno Copa, um texto intitulado "Selecinha! Culpa da L'Oréal". Naquele momento, a seleção ainda não havia garantido classificação para a fase seguinte, e um possível 'tropeço' contra camarões poderia colocar o Brasil na dependência dos resultados de outros jogos. No texto de Simão, ao discutir possíveis motivos para o "jogo de comadres" entre México e Brasil, o autor dispara: “É culpa da L'Oréal! Neymar e Daniel Alves, em vez de treinar, vão pintar cabelo" (Simão, 2014, p.

${ }^{9}$ Jornalista, colaborador do jornal "Folha de São Paulo" desde 1987, Simão é ainda colaborador da BandNews FM, apresentando diariamente "Buemba, Buemba", uma coluna que comenta em tons de sátira as principais notícias do dia (Simão, 2018). 


\section{BIFALAND, A CIDADE MALDITA ALLAN SIEBER}

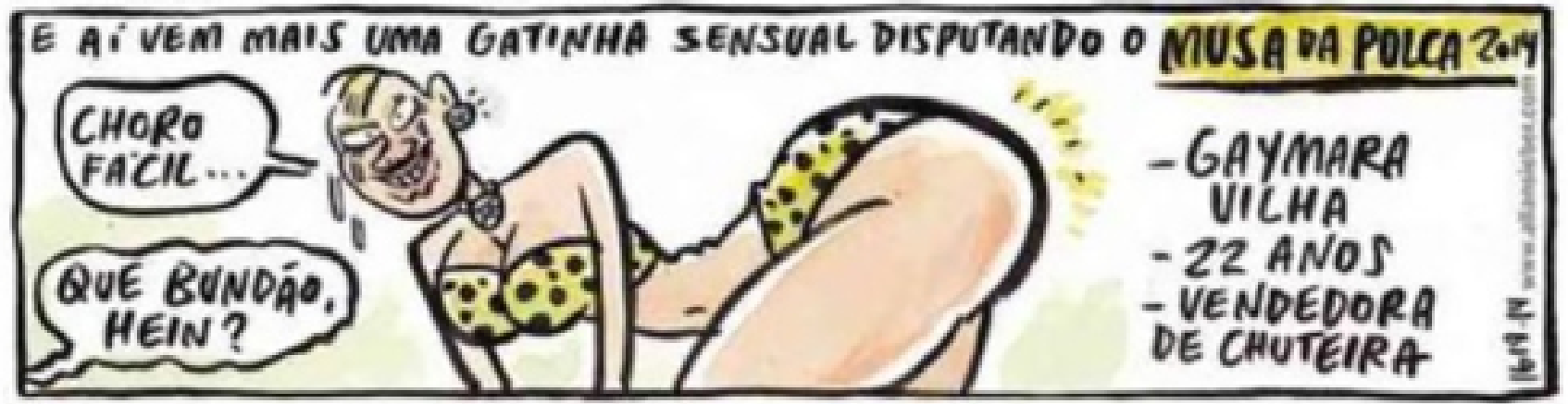

Imagem 2. "Musa da Polca 2014"

Fonte: Sieber, Folha de São Paulo, 02/07/2014a, p.E11

D9). Nas vésperas da partida, os atletas em questão teriam alterado corte e coloração dos cabelos, motivo de alvoroço na mídia esportiva (Extra, 2014). De acordo com José Simão, prática fútil, digna de zombaria em caso de performance duvidosa.

Em 26/06, três dias após o jogo que classificou o Brasil (Brasil x Camarões) como primeiro do grupo, dois dias antes da partida que daria acesso à próxima fase do campeonato, a 'Folha' publica:

A paródia de Neymar Júnior construída pelo cartunista Allan Sieber ${ }^{10}$ é Gaymar Filho, um sujeito cujas características em realce mencionam os 'excessos' daquele que deveria ser o representante máximo da seleção brasileira. Com cabelo loiro em estilo "moicano" e brinco na orelha esquerda, Gaymar seria uma das figurinhas de um álbum de personalidades paralelo ao da Copa, o "Álbum dos Figurinhas da Polca". O tom jocoso e o riso fácil despertado pelas personagens do álbum são balizadas pelo teor excêntrico invocado por aquilo que é considerado inadequado para um jogador de futebol. A vaidade manifestada nos adereços e no cuidado com o cabelo deslocam por meio da inadvertência dos códigos de gênero, Neymar para a condição de 'outro', para a condição de diferente. De modo mais específico, em meio ao maior megaevento esportivo do planeta protagonizado por homens, Neymar é advertido por transitar por aquilo que historicamente se atribui ao universo feminino.

Cabe ainda destacar que a emergência de "Gaymar" se dá justamente quando a seleção brasileira avança às oitavas de final, fase a partir da qual a derrota implicaria na eliminação sumária da competição. $O$ sentimento de desconfiança parece ser agravado com o anúncio do próximo adversário, o Chile, equipe que estaria, até aquele momento, se apoiando em um desempenho

\footnotetext{
${ }^{10}$ Artista Plástico, Cartunista e roteirista porto alegrense, nascido em 1972. Entre 2005 e 2017, publicou na Folha de São Paulo as tirinhas "Preto no Branco" e "Bifaland, a cidade maldita" (Sieber, 2018).
}

consistente. Apesar de classificada em 20 lugar na fase de grupos, a equipe chilena foi a responsável pela eliminação precoce da seleção espanhola, vencedora da Copa do Mundo de 2010. Naquele momento, a expectativa do hexacampeonato já teria cedido espaço a publicações que evidenciariam o clima de tensão e sufoco durante as partidas, sintoma de "descontrole emocional dos jogadores" (Dieder et al., 2016).

Com empate em $1 \times 1$ no tempo regulamentar, a partida foi decidida nos pênaltis. Com placar final em $3 \times 2$ do Brasil sobre o Chile, a seleção estaria classificada para as quartas de final.

Dois dias antes da partida entre Brasil e Colômbia, Allan Sieber apresenta "mais uma gatinha sensual disputando o Musas da Polca 2014":

Com o mesmo moicano loiro, com o mesmo brinco na orelha esquerda "Gaymara Vilha", emerge como uma variação da personagem "Gaymar". Dotada de uma feminilidade sensual, a personagem da tirinha assinada por Siebel parece elevar a outro patamar as ironias manifestadas na publicação do dia 26/06. Assim, o garoto ex-cabeleireiro chamado jocosamente Gaymar, dá origem à representação de uma garota seminua em pose sensual, cujo corpo volumoso em nádegas e seios materializa representações de mulher de 'moral mundana'. Das vestimentas, à pose, das formas do corpo às lágrimas nos olhos, a candidata à "musa da Polca 2014", parece incorporar aquilo que historicamente tem sido considerado um dos elementos mais depreciativos das identidades femininas, a sexualidade desmedida (Sales; Paraíso, 2013; Díaz-Benítes, 2019).

No mesmo dia 02 de julho de 2014, uma outra publicação de Sieber (2014b) chama atenção. Com o mesmo enfoque, escreve em tons de saudosismo "A volta do antigo Felipão" - homem que seria capaz de colocar nos eixos um conjunto de rapazes que estariam mais preocupados com as 'firulas midiáticas', 
como indicado por Denise Fraga ${ }^{11}$ e José Simão (2014, p. E9), do que com o compromisso e com a honradez esperada de atletas de futebol.

Conhecido por seu histórico de falta de polidez e traquejo, o 'abrupto' Luiz Felipe Scolari teria, enquanto técnico da seleção brasileira, na copa de 2014, adotado uma postura mais comedida ${ }^{12}$. Para Sieber, entretanto, o rigor e truculência poderiam ser possíveis maneiras para alinhar a equipe. De acordo com o cartunista, aos berros, Felipão diria: "Escutem só suas bailarinas: vocês ganham uma FORTUNA pra correr e fazer gol, então por que não correm nem fazem gol?! E SEM CHORADEIRA!!!" (Sieber, 2014b, p. D2, grifos do autor).

Assim como na representação de Gaymara, em "a volta do antigo Felipão", Sieber faz menção ao choro dos atletas como mais um elemento que iria evidenciar os deméritos e falhas de comportamento dos atletas, ou seja, o choro revelaria a ausência de temperamento estável e de posturas sóbrias capazes de lidar de modo austero com as intempéries de uma competição do porte da Copa do Mundo. De modo geral, essa manifestação não se tornou uma particularidade de Siebel, nem mesmo da Folha de São Paulo. Acompanhado de uma performance questionável, o choro seria apontado como falta de determinação e incapacidade de resolver os problemas técnicos e táticos do campo esportivo, deste modo, de acordo com Araújo (2015, p. 153), o imperativo "engole o choro e vai pra cima" tornou-se um lugar comum da mídia esportiva ao longo dos jogos de 2014.

Como recurso capaz de reestabelecer o desempenho necessário ao espetáculo, o "antigo Felipão" deveria, sobretudo, normatizar as condutas masculinas. Assim a identificação dos jogadores como "bailarinas" seria o recurso capaz de gerar nos atletas o estranhamento de suas próprias condutas, seja na performance esportiva, ou nos modos de se portarem. Leveza, graciosidade e delicadeza, associadas ao Ballet, serviriam como exemplo daquilo que não se deve ser, serviriam de estímulo, via negação e desprezo, para o retorno de uma conduta coerente com as referências de masculinidade forjadas pelo esporte - elemento suficiente para garantir um bom desempenho no futebol.

11“Nosso protagonista, Neymar, tem demonstrado muita intimidade com as câmeras [...] Depois dos gols, nosso craque continua lá, imbuído de seu personagem Calvin Klein de poucos sorrisos, fazendo do campo sua passarela exclusiva" (Fraga, 2014, p. D9).

${ }^{12}$ Em entrevista coletiva após a difícil classificação do Brasil sobre o Chile, o técnico Felipão teria declarado que sua postura estaria sendo 'cordial demais', dando indícios ao retorno de sua conduta mais agressiva (Globo Esporte, 2014).
Nessa direção, Siebel e a "Folha de São Paulo" se investem da posição dos "gozadores" que outorgam para si a faculdade de colocar na condição de rizível aqueles que atentem contra as condutas consideradas adequadas (Gastaldo, 2010) as quais, no caso deste estudo, seriam as de desempenhar performances compatíveis a de atletas de seleção. Nesse processo a paródia e a chacota acionam relações de poder que marginalizam aquilo que historicamente é associado às mulheres e aos homens homossexuais, deslocando para periferia Gaymara e as bailarinas da seleção.

Assim, ao passo que o mal desempenho dava indícios de uma eminente eliminação, o desapontamento e a insatisfação parecem ter autorizado a produção de representaçõesqueintencionamironizare desqualificar mediante aquilo que é considerado próprio das mulheres e dos homossexuais, intencionando como efeito, condutas reguladas, manutenção de hierarquias e justiça social. Em última instância, reifica a condição marginal daqueles e daquelas considerados 'outros', 'diferentes', 'excêntricos' ${ }^{13}$ (Louro, 2012).

\section{TECENDO CONSIDERAÇÕES}

Ao longo de 30 dias de jogos, nas publicações da 'Folha', as representações de gênero e sexualidades não normativas foram publicadas em número reduzido e de forma pontual. Assim, por meio de passagens breves e situadas no lugar do 'não sério', "Gaymara" e as "bailarinas da seleção" emergem para evocar o riso e o deboche. Parte fundamental à afirmação e reafirmação da referência masculina heterocentrada, 'o desviante', ao mesmo tempo em que deve ser exposto e anunciado, como ameaça latente, sua presença deve ser contida e regulada, afinal, identidades excêntricas podem perturbar e problematizar as pretensas noções de universalidade, unidade e estabilidade sugeridas pela heteronormatividade.

Assim, mecanismos linguísticos da paródia e da caricatura são estrategicamente acionados a fim de provocar o riso que anuncia, expõe e tenta corrigir a conduta daqueles sujeitos invigilantes, ao mesmo tempo em que reifica códigos de conduta associados ao futebol.

A análise do material produzido pelo jornal indica que o desempenho mediano, teria autorizado publicações que tentam deslocar para fora do centro os

\footnotetext{
${ }^{13}$ As últimas publicações de masculinidades desviantes relacionadas ao futebol na Folha datam do dia 02/07/2014. No dia 04 de julho, o Brasil disputou a classificação para as semifinais com a Colômbia, partida na qual Neymar se lesiona e abandona a competição. Em decorrência disso, a mídia esportiva, em tons de comoção nacional, passa a acolher o ídolo (Faller, 2014). Na Folha de São Paulo, as circunstâncias que cerceiam Neymar, a partir de sua lesão, parecem desautorizar chacotas e zombarias destinadas ao atleta a partir de então.
} 
atletas da seleção brasileira. Entretanto, cabe ressaltar que, nem Neymar, nem os demais integrantes da equipe do Brasil devem ser concebidos como abjetos. $O$ argumento aqui desenvolvido toma as representações de masculinidades dissidentes como uma estratégia que parece tentar desloca-los para fora do centro, localizando-os num gradiente de normalidade, cuja ordenação toma por base o grau de transgressão (identificados aqui como desempenho insuficiente e condutas pouco comedidas) e sua intersecção com outros marcadores sociais (classe, raça, dentre outros) (Dal'igna, 2011; Lopes, 2009) ${ }^{14}$.

Mesmo sendo alvos de zombarias, as paródias "Gaymara" e as "bailarinas da seleção" são associadas a homens atletas de futebol e suas inegáveis prerrogativas, o que inviabiliza compreendê-los como excêntricos, mesmo quando o desempenho esportivo não é suficiente.

Por outro lado, tais representações funcionam como produções culturais que reiteram 'os outros' e 'outras' como marginais. Reforçam barreiras a não heterossexualidade no futebol; inibem e constrangem a inserção e permanência das mulheres no esporte. Assim, o desempenho medíocre e a conduta 'extravagante' permitem, como recursos norteados pela heteronormatividade, a piada e o riso, cujos efeitos contribuem para a manutenção da matriz masculina e heterocentrada do futebol.

\section{REFERÊNCIAS}

Araújo J. Engole o choro e vai pra cima: Masculinidade e repercussão midiática da atuação brasileira na Copa do Mundo da Fifa de 2014. Estudos em Jornalismo e Mídia. 2015 [citado em 19 mai. 2019];12(1):153-161. Disponível em: https://periodicos.ufsc.br/index.php/jornalismo/ article/view/1984-6924.2015v12n1p153

Brinati F. Seleção Brasileira, identificação nacional e imprensa: a representação do 'Mineiratzen' na Folha de S. Paulo e em O Globo. Estudos em Jornalismo e Mídia. 2014;11(2):402-414.

Britzman D. O Que é Essa Coisa Chamada Amor: identidade homossexual, educação e currículo. Educação e Realidade. 1996 [citado em 19 mai. 2019];21(1):71-96. Disponível em: http://www.ufrgs.br/edu_realidade

Butler J. Problemas de Gênero: feminismo e subversão da identidade. Rio de Janeiro: Civilização Brasileira; 2003.

Camargo W. Entre o óbvio e o escamoteado: o futebol (masculino) em tempos de Copa. Novos Debates - fórum de debates em Antropologia. 2014;1:99-109.

Costa $M$, Andrade P. Na produtiva confluência entre educação e comunicação, as pedagogias culturais contemporâneas. Perspectiva. 2015 [citado em 19 mai. 2018];33(2):843862. Disponível em: https://periodicos.ufsc.br/index.php/ perspectiva/article/view/2175-795X.2015v33n2p843

\footnotetext{
${ }^{14} \mathrm{~A}$ noção de gradientes de normalidade recusa os pares binários 'normal'/'anormal'; 'centro/margem', evidenciando de outros modos os efeitos das relações de poder.
}

Dal'igna M. Família S/A: um estudo sobre a parceria famíliaescola [Tese]. Porto Alegre: Universidade Federal do Rio Grande do Sul; 2011.

Díaz-Benítez M. O gênero da humilhação. Afetos, relações e complexos emocionais. Horiz. Antropol. 2019; ano 25(54):51-78.

Dieder JA, Feltes AF, Jacques Junior MA, Kuhn Junior N, Sanfelice GR. O fracasso da seleção brasileira/2014 retratado pela Folha de S. Paulo. Movimento. 2016;22(4):1177-1194.

Escher T, Reis H. As relações entre futebol globalizado e nacionalismo: o exemplo da copa do mundo de 2006. Revista Brasileira de Ciências do Esporte. 2008;30(1):41-55.

Extra. Copa 2014: Neymar e Daniel Alves pintam o cabelo antes da partida contra o México. Extra Globo.com. 15 jun. 2014 [citado em 29 abr. 2018]. Disponível em: https://extra.globo.com/ esporte/copa-2014/copa-2014-neymar-daniel-alves-pintamcabelo-antes-da-partida-contra-mexico-12867834.html

Faller R. \#Somos todos Neymar: mobilização social no Twitter. Dito Efeito. 2014;5(7):1-13.

Figari C, Díaz-Benites M. Prazeres dissidentes. Rio de Janeiro: Garamond; 2009.

Figari C. Eróticas de la disidencia en América Latina: Brasil, siglos XVII al XX. 1a ed. Buenos Aires: Fundación Centro de Integración, Comunicación, Cultura y Sociedad - CICCUS: CLACSO; 2009.

Fischer R. O dispositivo pedagógico da mídia: modos de educar na (e pela) TV. Educação e Pesquisa. 2002[citado em 29 mai. 2018];25(1):151-162. Disponível em: http://www.scielo.br/ scielo.php?script=sci_arttext\&pid=S1517-97022002000100011

Foucault M. Ditos e Escritos IV: Estratégia Poder-Saber. Rio de Janeiro: Forense Universitária; 2013.

Fraga D. Sorria! Você está sendo filmado. Folha de São Paulo. 19 jun. 2014 [citado em 10 mai. 2018];D09. Disponível em: www1.folha.uol.com.br/.../denisefraga/.../1472731-sorriavoce-esta-sendo-filmado.shtml

Gastaldo É. As relações jocosas futebolísticas: futebol, sociabilidade e conflito no Brasil. Mana. 2019;16(2):311-325.

Globo Esporte. Felipão na copa: carinho na volta ao Grêmio e muitas polêmicas. 31 dez. 2014 [citado em 1 mai. 2018]. Disponível em: http://globoesporte.globo.com/rs/ noticia/2014/12/felipao-2014-7-1-na-copa--carinho-navolta-ao-gremio-e-muitas-polemicas.html

Goellner S. Mulheres e futebol no Brasil: entre sombras e visibilidades. Revista Brasileira de Educação Física e Esporte. 2005;19(2):143-151.

Hall S. The work of representation. In: Hall S, organizador. Representation.

ladevito P. Teorías de género y cine. Un aporte a los estudios de la representación. Universitas Humanística. 2014 [citado em 20 abr. 2019];78:211-237. Disponível em https:// revistas.javeriana.edu.co/index.php/univhumanistica/ article/view/6475/8199

Kuhn Junior N, Castilhos D, Montin JM, Sanfelice GR. Framing the 2013 FIFA Confederations Cup Finals by the Folha de São Paulo Newspaper. American International Journal of Contemporary Research. 2015;5:18-26.

Laqueur T. Inventando o sexo: corpo e gênero dos gregos a Freud. Rio de Janeiro: Relume Dumará; 2001.

Lopes M. Políticas de inclusão e governamentalidade. Educação \& Realidade. 2009;34(2):153-169.

Louro G. "Currículo, gênero e sexualidade: o 'normal', o 'diferente' e o 'excêntrico'". In: Goellner S, Oliveira J, Louro 
G. Corpo, Gênero e sexualidade: um debate contemporâneo na educação. 8a Ed. Petrópolis: Vozes; 2012. p. 41-52.

Louro G. Um corpo estranho: ensaios sobre sexualidade e a teoria Queer. Belo Horizonte: Autêntica; 2008.

Meyer D, Soares R. Corpo, gênero e sexualidade nas práticas escolares: um início de reflexão. In: Meyer D, Soares $R$, organizadoras. Corpo, gênero e sexualidade. Porto Alegre: Mediação; 2004. p. 5-16.

Meyer D. Educação, saúde e politização da maternidade. In: Silveira RMH, organizadora. Cultura, poder e educação: um debate sobre os Estudos Culturais em Educação. Canoas: Editora da Ulbra; 2005. p. 145-164.

Mezzaroba C, Pires GL. Os Jogos Pan-Americanos Rio/2007 e o agendamento midiático-esportivo: um estudo de recepção com escolares. Revista Brasileira de Ciência do Esporte. 2011;33(2):337-355.

Preciado B. La invención del género, o el tecnocordero que devora a los lobos. Em Conversaciones Feministas, Biopolítica. 2009;15-38.

Ribeiro C, Siqueira V. O novo homem na mídia: ressignificações por homens docentes. Revista Estudos Feministas. 2007;15(1):217-241.

Sabat R. Pedagogia cultural, gênero e sexualidade. Revista Estudos Feministas. 2001;9(1):4-21.

Sales SR, Paraíso MA. O Jovem macho e a Jovem Difícil: governo da sexualidade no currículo. Educação \& Realidade. 2013 [citado em 7 mai. 2020];38(2):603-625. Disponível em: http://www.ufrgs.br/edu_realidade

Sanfelice GR, Montin JM, Oliveira Junior L, Feltes AF, Kuhn Junior Norberto. Análise comparativa entre os jornais EI
País e Folha de S. Paulo na final da Copa das Confederações. Movimento. 2014;20:177-196.

Scott J. Gênero: uma categoria útil de análise histórica. Educação \& Realidade. 1995;2(20):71-100.

Sieber A. A volta do antigo Felipão. Folha de São Paulo. 2 jul. 2014b [citado em 4 mar. 2015];D2. Disponível em: www1. folha.uol.com.br/fsp/esporte/174126-a-volta-do-antigofelipao.shtml

Sieber A. Allan Sieber. 2018 [citado em 30 abr. 2018]. Disponível em: www.allansieber.com.br

Sieber A. Musas do Polca 2014. Folha de São Paulo. Folha de São Paulo. 2 jul. 2014a [citado em 4 mar. 2015];E11. Disponível em: www1.folha.uol.com.br/fsp/esporte/174126-musada-polca.shtml

Sieber A. Os figurinhas da Polca. Folha de São Paulo. 26 jun. 2014 [citado em 4 mar. 2015];E09. Disponível em: www1. folha.uol.com.br/fsp/esporte/174126-os-figurinhas-dapolca.shtml

Simão J. Blog do Simão. 2018 [citado em 19 mai. 2018]. Disponível em: https://blogdosimao.blogosfera.uol.com.br/

Simão J. Selecinha! Culpa da L'Óreal. Folha de São Paulo. 19 jun. 2014 [citado em 4 mar. 2015];D9. Disponível em: www1. folha.uol.com.br/fsp/esporte/174126-selecinha-culpa-daloreal.shtml

Swain TN. Feminismo e recortes do tempo presente: mulheres em revistas 'femininas'. São Paulo em Perspectiva. 2001;15(3). 